\title{
Drawing everyday sexism in academia: observations and analysis of a community-based initiative
}

\author{
Marie Bocher $^{1}$, Martina Ulvrova ${ }^{1}$, Maëlis Arnould ${ }^{2}$, Nicolas Coltice ${ }^{3}$, Claire Mallard ${ }^{4}$, Mélanie Gérault ${ }^{5}$, and \\ Alice Adenis 6 \\ ${ }^{1}$ Institute of Geophysics, Department of Earth Sciences, ETH Zurich, Zurich, Switzerland \\ ${ }^{2}$ Centre for Earth Evolution and Dynamics, University of Oslo, Oslo, Norway \\ ${ }^{3}$ Laboratoire de Géologie, Ecole Normale Supérieure, Paris, France \\ ${ }^{4}$ Earthbyte Research Group, School of Geosciences, The University of Sydney, Sydney, Australia \\ ${ }^{5}$ Earth, Atmospheric and Planetary Sciences, MIT, Cambridge, USA \\ ${ }^{6}$ Dataswati, Massy, Ile-de-France, France
}

Correspondence: Did this really happen?! team (mail.didthisreallyhappen@ gmail.com)

Received: 30 November 2019 - Accepted: 3 February 2020 - Published: 2 April 2020

\begin{abstract}
Sexist behaviour in the workplace contributes to create a hostile environment, hindering the chance of women and gender non-conforming individuals to pursue an academic career, but also reinforcing gender stereotypes that are harmful to their progress and recognition. The Did this really happen?! project aims at publishing real-life, everyday sexism in the form of comic strips. Its major goal is to raise awareness about unconscious biases that transpire in everyday interactions in academia and increase the visibility of sexist situations that arise within the scientific community, especially to those who might not notice it. Through the website didthisreallyhappen.net, we collect testimonies about everyday sexism occurring in the professional academic environment (universities, research institutes, scientific conferences...). We translate these stories into comics and publish them anonymously without any judgement or comments on the website. By now, we have collected over 100 testimonies. From this collection, we identified six recurrent patterns: (1) behaviours that aim at maintaining women in stereotypical feminine roles, (2) behaviours that aim at maintaining men in stereotypical masculine roles, (3) the questioning of the scientific skills of female researchers, (4) situations where women have the position of an outsider, especially in informal networking contexts, (5) the objectification of women, and (6) the expression of neosexist views. We first present a detailed analysis of these categories, then we report on the different ways we interact and engage with the Earth
\end{abstract}

science community, the scientific community at large and the public in this project.

\section{Introduction}

As in the rest of society, sexism is still pervasive in academia (Troy, 2019). Most STEM (Science, Technology, Engineering, and Mathematics) fields are traditionally maledominated and the diverse expressions of gender bias tend to maintain this status quo (Williams et al., 2014; Asplund and Welle, 2018). This is the case for Earth and Planetary Sciences where women represent between $32 \%$ and $42 \%$ of the academic community (according to numbers on American Geophysical Union (AGU) Fall Meeting participation from 2014 to 2016 (Ford et al., 2018), on European Geosciences Union (EGU) General Assembly and AGU Fall meeting participation in 2018 (Popp et al., 2019) and a volunteer-based survey of the gender of abstract first authors at the EGU General Assembly 2019).

Gender bias contributes to this underrepresentation in three ways. First, it can lead to discrimination during recruitment (Moss-Racusin et al., 2012; Sheltzer and Smith, 2014), promotion (Régner et al., 2019), grant evaluation (Kaatz et al., 2016) and the article reviewing process (Lerback and Hanson, 2017) although their role in the underrepresentation of women in academia has been contested (Ceci et al., 2014). Second, it can lead to an underestimation of female achieve- 
ments, merits and performance (Dutt et al., 2016; Chávez and Mitchell, 2019). Finally, sexist behaviours and sexual harassment have a deterrent effect for female and gendernonconforming individuals when considering attending specific events or even pursuing an academic career (John et al., 2016; Clancy et al., 2017; Biggs et al., 2018; Moss-Racusin et al., 2018; Dyer et al., 2019).

Ignoring gender bias does not make it disappear. On the contrary, in a statistical analysis of the national promotion scheme of french CNRS researchers, Régner et al. (2019) showed that women's promotion was less frequent when academic committees did not believe in the existence of gender bias. That corroborates other studies showing that individuals who believe that they are objective show more bias (Uhlmann and Cohen, 2007). Likewise, merely stating that an institution is meritocratic has been shown to lead to more gender bias in promotion decisions (Castilla and Benard, 2010).

Institutional measures that address the mechanism of gender bias and improve gender diversity in academia are well documented (e.g. Moss-Racusin et al., 2014; Monroe et al., 2014; Greider et al., 2019; Buitendijk et al., 2019; Williams, 2019). However, one necessary condition of the application of such measures is that the Earth science community at large, and especially those in a situation of power are convinced that they are needed and that they are a priority. That is why we consider that the recognition and apprehension of gender bias (implicit or explicit) is still a crucial factor to reach gender parity and equality of treatment in the Earth science community.

The project Did this really happen?! (DTRH) emerged from the need to share experiences of gender bias, first as Earth scientists, within our laboratory and with our direct collaborators and colleagues (Bedford, 2018). We are a team of seven scientists, of which six are early-career women, formed in 2016 around a research project studying the dynamics of the Earth's mantle convection and plate tectonics. Initially, we started discussing gender biases during internal group meetings and realised that we had all encountered similar sexist jokes since the start of the project. To dig deeper into this topic, we invited two members of the local university diversity and equality service: Philippe Liotard and Chloé Schweyer to our discussions. In the meantime, the principal investigator (PI) of the project was solicited to talk about the management of his team at an EGU General Assembly session and we decided to present our experiences as a mostly feminine research team (Coltice and Bocher, 2016). In 2017, we presented a second poster at the same session (Arnould et al., 2017), on which we decided to draw comics about the sexist situations faced by each of us, thanks to the talent of Alice Adenis (Adenis, 2019) who had joined the team in the meantime. This was initially a way to draw people's attention to our stories. Given the success of the poster and the comic strips, we decided to extend the project by collecting sexist stories from the academic community, and turning these stories into comics. In doing so, we want to give greater visibility to this problem, which many scientists face.

One of the challenges to bring awareness about gender bias issues is that prejudice tends to be minimised by people who are not concerned or benefit from it. For example, males tend to doubt and question studies showing gender bias more than women do (Handley et al., 2015). More anecdotally, this is illustrated by a comment we received on our facebook page: "Having been to lots of science conferences (and being a man) I have never encountered this sort of attitude, but I guess it exists, unfortunately.” Moreover, although efforts have been globally conducted to improve male-female equity, the results of Haines et al. (2016) seem to indicate very limited changes in gender stereotypes since the 1980s. Based on our experience, we acknowledge that it is difficult to recognise gender-stereotypical behaviours: such behaviours are deeply anchored in our society, our cultural habits, our education and are, therefore "internalised by both men and women" (Hentschel et al., 2019). However, identifying a situation as sexist is the first step to interventions (Ashburn-Nardo and Abdul Karim, 2019; Valian, 2019). We believe that comics and illustrations of what everyday sexism looks like provide a complementary approach to statistics of real-life experiences and accounts of controlled experiments to raise awareness about unconscious biases.

The core of the Did this really happen?! project is descriptive: we want to show concrete examples of everyday sexism in academia, following the idea that it is easier and more recreational to read a comic strip rather than a plain text about a sexist behaviour. Although our collection of comic strips does not cover the whole range of sexist situations encountered in academia, we believe it can serve as a support for further discussions on the topic. We collect testimonies of sexism happening in academia via the website https://didthisreallyhappen.net/ (last access: 9 March 2020, DTRH team, 2019a), and translate them into comics. The process of creating a comic strip from collected testimonies and an analysis of the testimonies received so far are provided in Sect. 2. We have also experimented with different ways to communicate on the project in various contexts to improve consciousness on sexist biases. We report on our communication and community engagement activities in Sect. 3 and comment on their impact. Further, we put our project in a larger context of describing the different types of sexism in academia and finding strategies to minimise gender biases at different levels in our society in Sect. 4.

\section{Treatment, classification and analysis of received testimonies}

Testimonies of everyday sexism in academia are mainly collected through our website platform, although the first testimonies were gathered from our own experiences. Figure 1 shows the procedure to process a testimony. It ensures that 


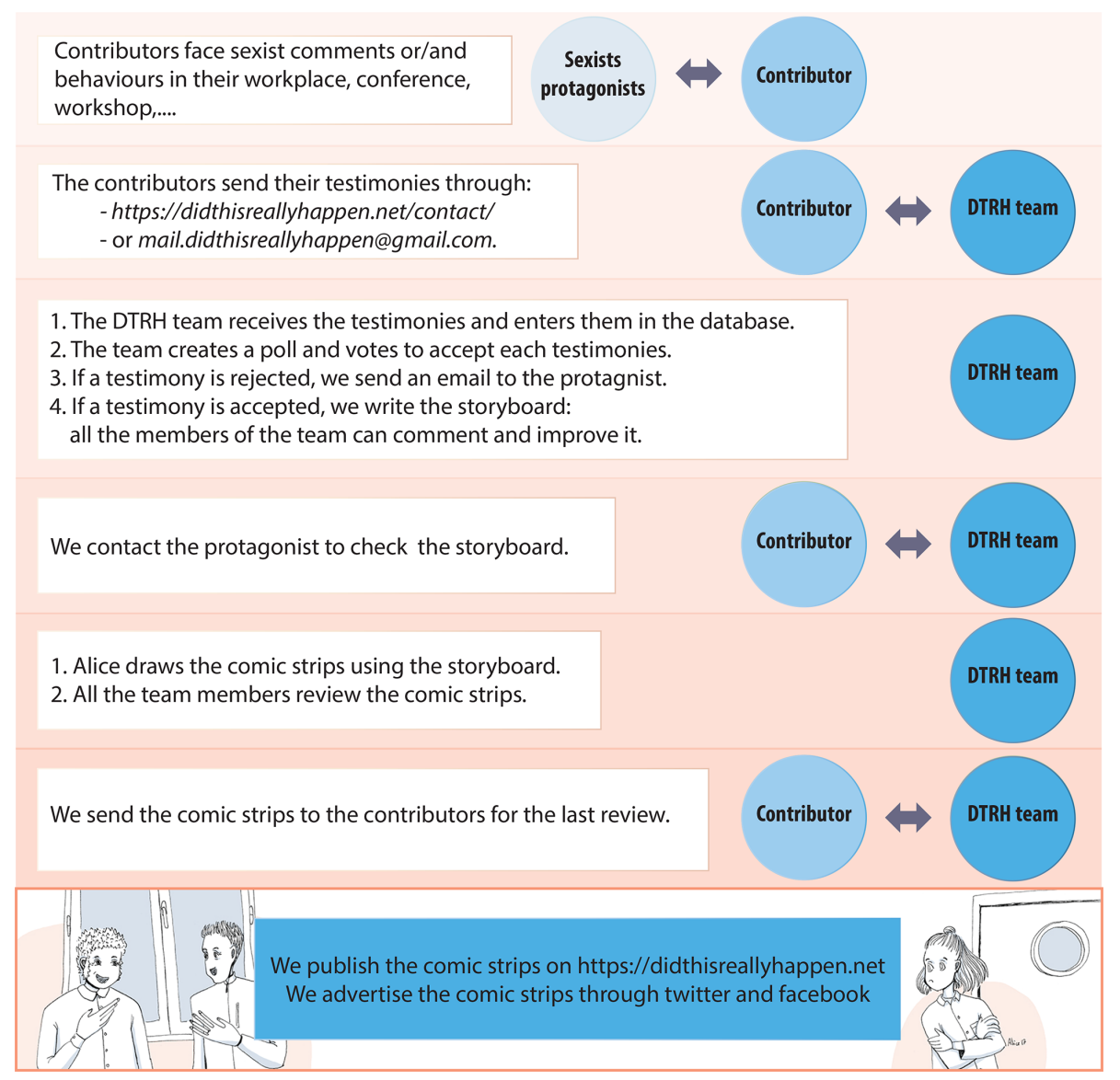

Figure 1. Procedure of creation of a comic strip from the testimony of a given contributor. All comics are hand-drawn by Alice Adenis distributed under the Creative Commons Attribution 4.0 License. DTRH stands for Did this really happen?!.

the comic strips are depicting the situation as experienced by the contributor who contacted us while preserving their anonymity. First, we collectively assess the validity of each received testimony using three main criteria: (1) the story depicts a situation of sexist bias, (2) the story is different from the comic strip that has already been published (3) it is possible to tell this story within a short strip of maximum five drawings. Upon acceptance of each testimony, we write a storyboard for artist Alice Adenis who draws the corresponding comic strip. Before and after the drawing stage, we exchange with the contributor to verify the realism of the expressions of all characters in the cartoon and the faithful depiction of the drawn situations. We also ensure that the desired level of anonymity is respected. After final approval of the comic strip by the contributor and members of the team, it is published and advertised on both our website and social media.

In this section, we present a description and propose a classification of the different types of sexism that appear in the collected testimonies. Since we rely on voluntary self-report and advertise our initiative through personal and professional networks, this classification should not be interpreted as an exhaustive list of all existing sexist biases, but rather as a synthetic way to interpret the testimonies that we received so far.

\subsection{Received stories and proposed classification}

Between 2016 and 2019, we received 103 testimonies, from which we accepted 89 stories. So far, 24 stories have been turned into comic strips and published online on our webpage. Two of them $(2.2 \%)$ were written by men while 87 stories (representing $97.8 \%$ of all accepted contributions) were shared by women. Interestingly, most of the received testimonies are proposed by both early-career scientists (post-doctoral fellows and PhD students) and full professors (Fig. 2). One plausible explanation is that full professors are the ones who likely encountered more sexist situations during their career and that early-career scientists are more preoccupied with and more aware of gender biases due to the recent birth of international feminist movements such as \#MeToo that received a lot of public attention.

The analysis of the testimonies points to sexist behaviours being the expression of gendered stereotypes that are still strongly anchored in our scientific community as they are in 


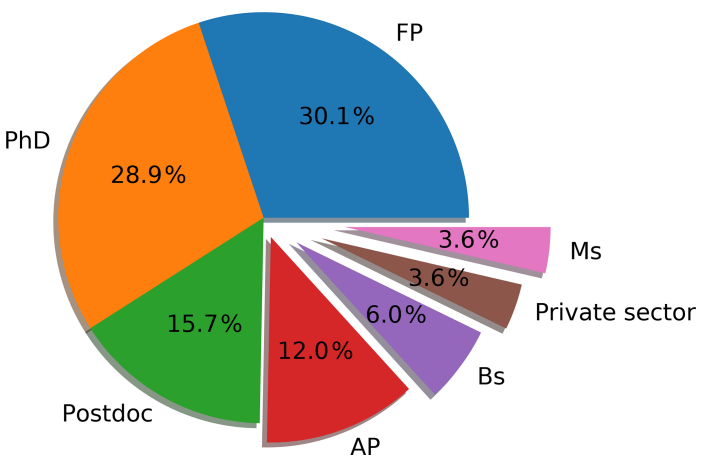

Figure 2. Career level of the authors of the accepted testimonies. FP stands for full professor, $\mathrm{PhD}$ for $\mathrm{PhD}$ student, Postdoc for postdoctoral fellow, AP for assistant or associate professor, Bs for bachelor student, Private sector for contributors working outside academia and Ms for master student.

the rest of the society. One of the most fundamental and still deeply rooted dichotomies associated with masculinity and femininity is the agency versus communality opposition (e.g. Haines et al., 2016; Hentschel et al., 2019). According to social role theory (Eagly and Wood, 2012), men would be more agentic (meaning that they are more likely characterised by assertiveness, independence, instrumental competence and leadership competence), while women would be more communal (they would be more inclined to feel more concern for others, sociability and emotional sensitivity). Such stereotypes do exist in the scientific environment, as we show in the following sections.

New ways of expressing prejudice against women are modern sexism (Swim et al., 1995) or neosexism (Tougas et al., 1995). Becker and Swim (2011) explain that both terms describe covert forms; the first one recognises that gender bias exists but its importance is minimised; the second one arises from the pressure between gender egalitarian beliefs and negative feelings against women.

These different types of sexism take form through persisting stereotypes, which appear in the testimonies we received. The distinct gender biases associated with each story can be described using several classifications. Binary classifications include but are not limited to: (1) implicit (automatic and unconscious) versus explicit (conscious and willingly reported, e.g. Miller et al., 2014), (2) descriptive (characteristics that women/men are believed to have) versus prescriptive (characteristics that women/men should have, e.g. Burgess and Borgida, 2000) and (3) benevolent (expression of sexism that appear to be positive, e.g. chivalry or the "womenare-wonderful effect" conceptualized by Eagly and Mladinic, 1994) versus hostile (sexist view expressed in term of hostile action or derogatory comments , e.g. Glick et al., 2000) sexist behaviours. Williams et al. (2014) identify four main gender biases encountered by women: (1) the Prove-It-Again, where women have to make more effort to establish their place compared to their male colleagues, (2) the Tightrope, where women struggle between adopting a masculine behaviour to be respected, seen as competent but unpopular and adopting a feminine behaviour to be liked but seen as incompetent, (3) the Maternal Wall, related to challenges with motherhood and (4) the Tug of War, related to the competition between women as a result of the aforementioned pressures. We propose a different classification that is based on finding recurrent patterns in the testimonies we collected but shares similar categories with the existing classifications. We identify six classes of sexist attitudes: (1) confining females to stereotypical roles, (2) confining males to stereotypical roles, (3) questioning female competencies, (4) keeping women as outsiders in networking contexts, (5) objectifying women and (6) neosexism as a backlash of antisexist policies. A more detailed analysis of these categories is provided in the following sections. We acknowledge the fact that this categorisation can be subjective. For instance, most female/male stereotypes are defined as opposites, so oftentimes we observe that in a given situation, both male and female stereotyping are at stake. Moreover, these categories are not exclusive, and several situations fall into several categories.

\subsection{The expression of female stereotypes}

$69 \%$ of the accepted stories (61 of them) involve behaviours that keep females into traditional roles. These roles are often not in relation to academic work. Many testimonies express the fact that within their research environment, women scientists are put back to a gendered condition defined upon physical stereotypes, among which are attractiveness ("Pretty face" and "Sympathetic and good looking" comic strips), wearing a bra (unpublished testimony), and being or becoming a mother ("anyway you will soon be busy with children" being one quote among others).

Other testimonies highlight cases establishing a domination relationship. One expression of such a bias is the fact that women are automatically categorised below males in the hierarchy. Sometimes male scientists associate female professors or editors to students ("Who's your advisor?" comic strip, cf. Fig. 3). Testimonies describe female senior professors in a meeting being automatically chosen to take notes (for instance "Who's taking notes?" comic strip). Sometimes, a female scientist is reduced to the wife/girlfriend of a man ("Grad school husband" comic strip).

We also received testimonies involving the traditional stereotype of females not being interested in science, or not having biological abilities for science by nature ("Conference wake up" comic strip for instance). Instead, a lot of testimonies show the stereotype of women being more qualified to do administrative tasks (such as taking notes, "Who is taking notes?" comic strip, or preparing the practical aspects of a field trip, "Field trip takeover" comic strip). Likewise, women tend to be assigned household-type tasks (cleaning the laboratory, preparing the meals or bringing the coffee dur- 

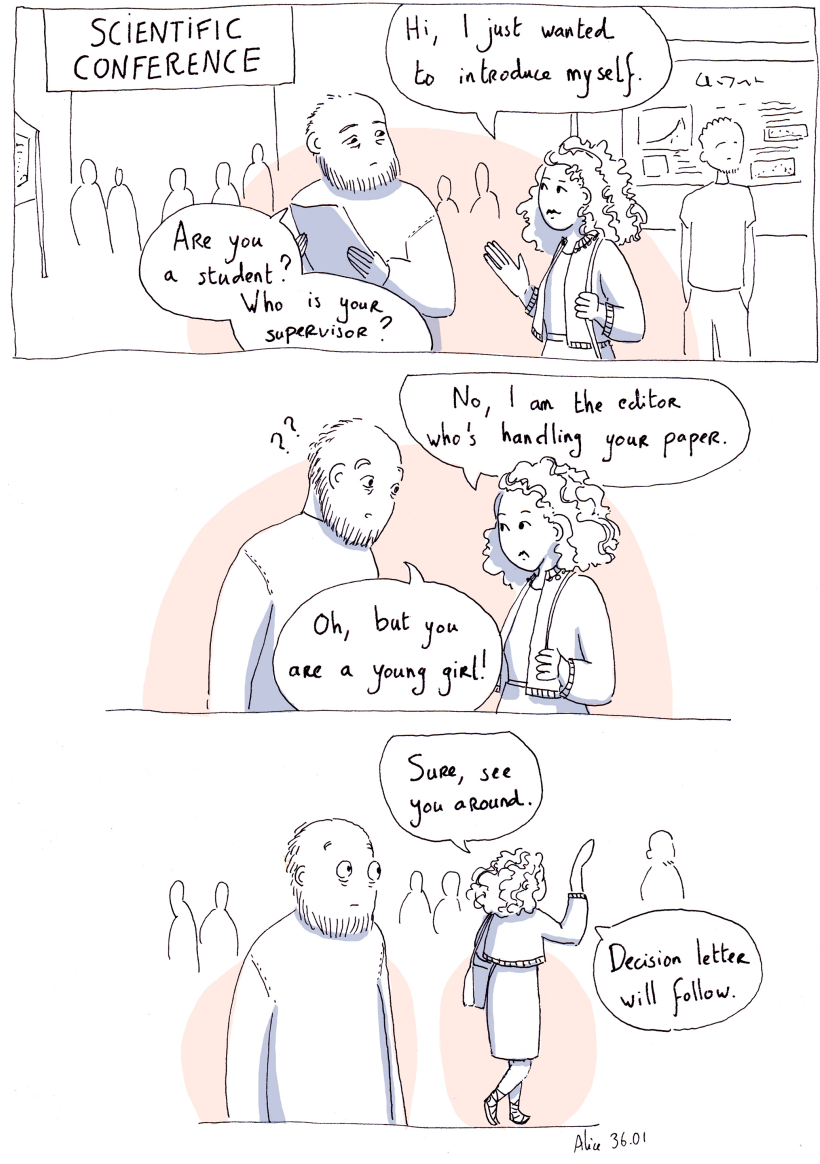

Figure 3. "Who's your advisor?" comic strip that falls into the "Female stereotypical roles" category. In this case, a female is considered at lower grade based on her appearance and gendered condition (DTRH team, 2019a; Adenis, 2019). All comics are hand-drawn by Alice Adenis - distributed under the Creative Commons Attribution 4.0 License.

ing workshops, meetings and field trips, "Field trip takeover" and "Who is taking notes?").

The 61 testimonies with such stereotypes show repetitions of the same situations for different age classes, countries and situations (conference, laboratory, teaching, meeting).

\subsection{Male stereotypes}

We identified 34 stories where descriptive or prescriptive stereotypes on males were at play ( $38 \%$ of the stories). Such stereotypes include seeing men as physically superior and competent individuals, and therefore better fitted for fieldwork than women: a testimony reported for example that male researchers were encouraged to do a field trip while females' capabilities were questioned. Positive masculine traits like being a leader and a decision-maker are at play in the "First author" comics, where a reviewer wrongly attributes the first authorship of the article they are reviewing to a male coauthor instead of the actual female first author.
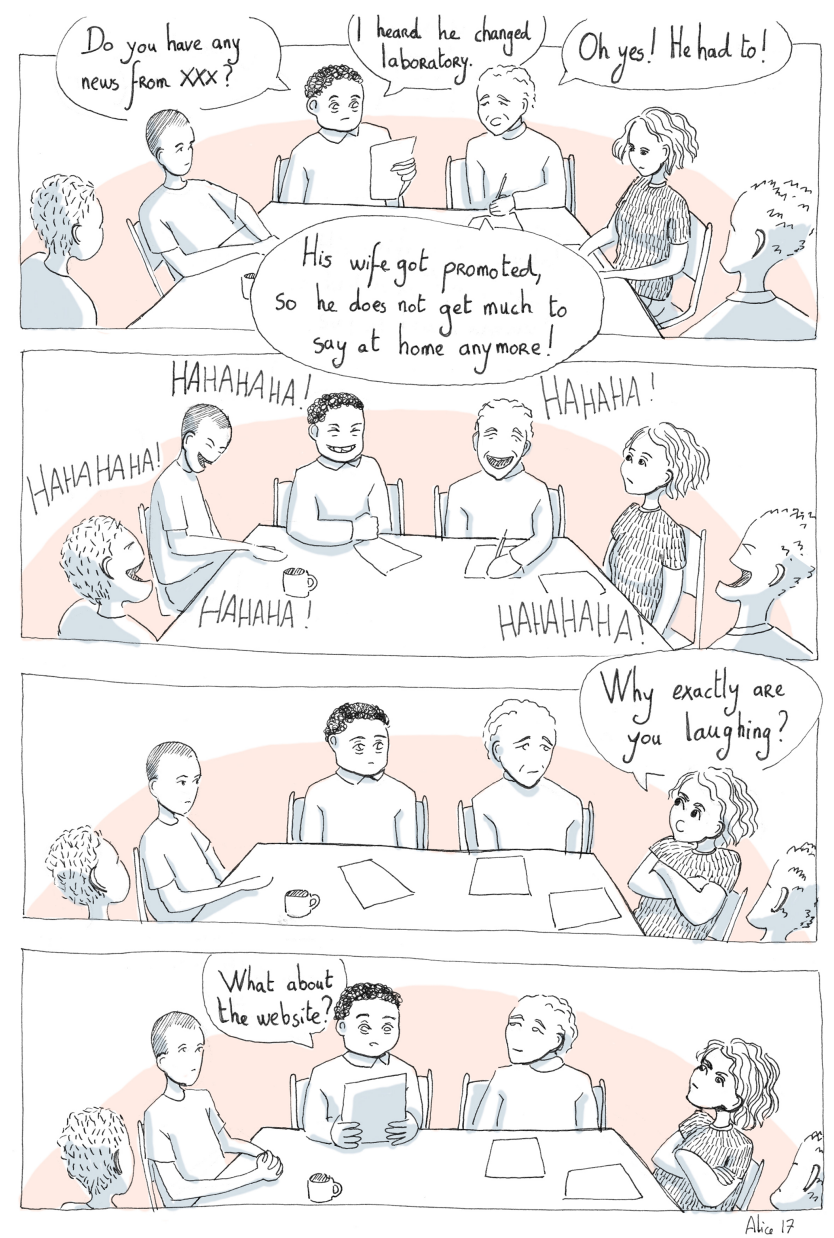

Figure 4. Example of "Male stereotypes" and "Women as outsiders in networking contexts" categories. Peers are laughing at a male colleague who supports his wife's career evolution. At the same time, a female scientist finds herself outside of the male fraternity circle. Comic strip title: "His wife got promoted" (DTRH team, 2019a; Adenis, 2019). All comics are hand-drawn by Alice Adenis - distributed under the Creative Commons Attribution 4.0 License.

The dominance of male researchers is also argued using erroneous biological arguments such as: "It's normal that men are more aggressive during discussions because they have more testosterone" ("Conference wake up" comic strip) or "Men and women are just better at different things. It's biology." (unpublished testimony) suggesting that men are better in STEM fields.

Failure to comply with stereotypical roles leads to strong reactions, such as in the comic strip entitled "His wife got promoted" (Fig. 4): the news that a man has relocated due to his wife's promotion is received with mockery by male colleagues, and he is considered as weak because he does not conform with the traditional male dominant role of the breadwinner.

Another common mechanism is to interpret male behavior and decisions as necessarily motivated by sexual inter- 




Figure 5. Example of the "Questioning female competence" category. A male colleague is putting the physical appearance of his female peer ahead of her qualification while playing down her scientific competence. Comic strip title: "Professor likes blondes" (DTRH team, 2019a; Adenis, 2019). All comics are hand-drawn by Alice Adenis - distributed under the Creative Commons Attribution 4.0 License.

est, such as in the comic strips entitled "Professor likes blondes" (Fig. 5) and "A man's world". Phrases such as: "Did you come with your harem" are used by peers to express men's power and sexual dominance when a male PI is working with a feminine team, and de facto normalise predatory sexual behavior.

\subsection{Questioning female competence}

We identified $57 \%$ of the accepted stories exhibiting questioning competencies of a female scientist (51 stories). A female researcher has to prove again and again her excellence in science and give more evidence that she is as competent as her male colleagues and deserves her position. This is partly a result of conflicting views on being feminine and being an expert in the field. Such a deeply rooted stereotype manifests itself in particular when it comes to obtaining distinguished recognitions from the community in the form of an award or a grant for example. Success is perceived with doubts and contested: "You know why you won the award? That's because they had to fill a female quota!" ("Female quota" comics).

Questioning of female professional qualities is especially striking in cases where success is attributed to the physical appearance of the female researcher. "Have you ever wondered if people just stop by [your poster] because of your pretty face?" ("Pretty face" comic strip) is an example of the depreciation of scientific success during a conference. "There were sure a lot of facts and figures in your talk, little lady." (comics "Little lady") is a condescending remark that a female researcher received after her talk, exposing her credibility and competencies. Female scientists are too often confronted with being judged by their appearance rather than scientific competence. "Oh, I guess he (the professor) likes blondes" (comic strip "Professor likes blondes", Fig. 5) that suggests that this male professor was working with a female researcher only because of her look.

Such comments come directly from close colleagues who work in the same research group, but also more indirectly from peers within the scientific community at large. An example of the latter is: "I never thought the author of this paper could be a woman!" (comic strip "Authorship"). This points towards the ubiquity of this social bias.

In addition, a recurring pattern in the stories arises when a man explains to his female colleague something in which the female scientist excels at herself and is very often even more competent. This so-called "mansplaining" (which involves males believing their expertise is more relevant than their female counterpart), is shown for example in the "Conference classics" comic strip.

\subsection{Women as outsiders in networking contexts}

We observed that about a quarter of testimonies (19 stories) depict situations in which female scientists are considered as marginal in the scientific community or as a different type of human beings. A recurrent situation shows male scientists meeting a group of people in which there is one or several women. Men greet each other but either overlook women or salute them in a different way, sometimes non-professional (e.g. "Nice headphones" comic strip).

Another recurrent situation in testimonies concerns the presence of one or two women in panels, boards or informal gatherings among a majority of men. In such a context, stories depict how male scientists interact with each other ignoring female scientists. The "His wife got promoted" comic strip or decisions made during an informal chat in the men's restroom (received testimony) are examples. Indeed, brotherhood is an important factor that reinforces males' position and leaves women outside this circle.

Some partial explanations of these situations are expressed in testimonies citing male scientists wondering how women behave, feel or react, as if they would be a different kind of human being. Again, this shows how work relationships can 

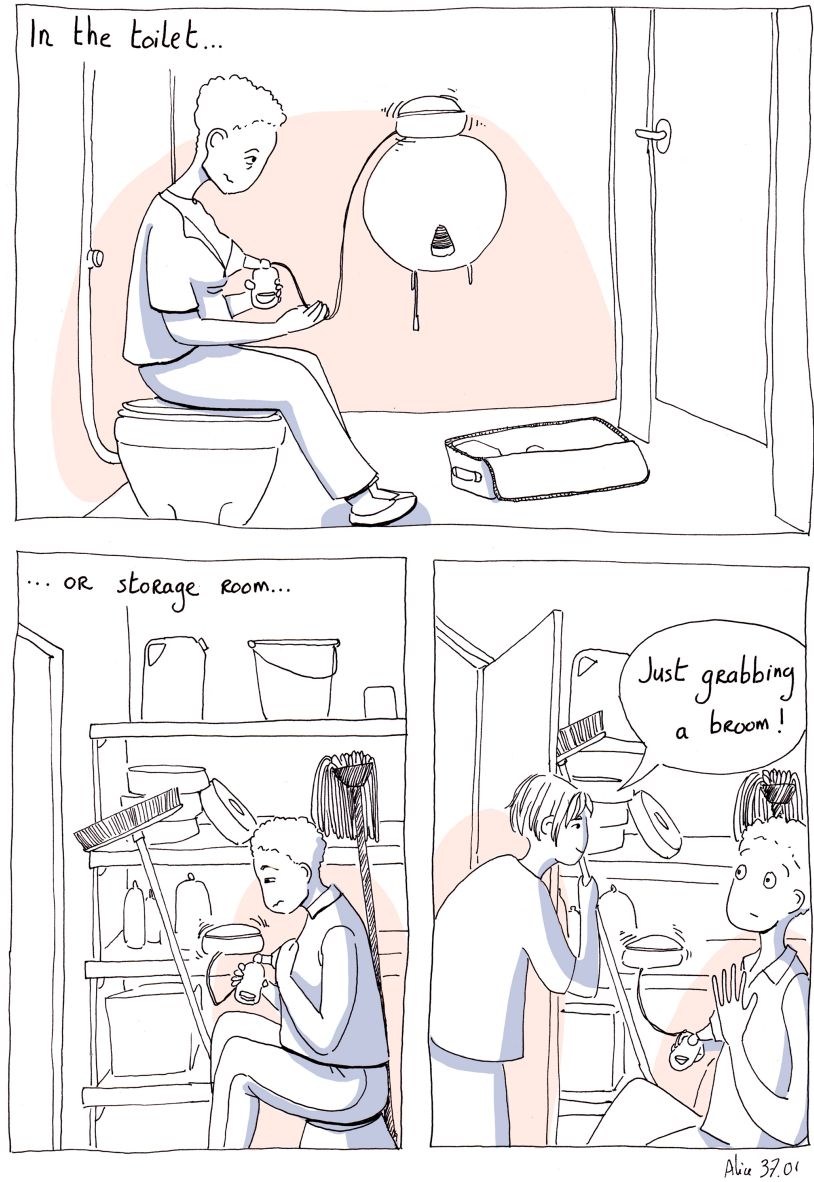

Figure 6. A female scientist finds herself isolated from the research community at a conference due to needs related to motherhood. Example of "Women as outsiders in networking contexts" stereotype. Comics title: "Breastfeeding at conferences" (DTRH team, 2019a; Adenis, 2019). All comics are hand-drawn by Alice Adenis - distributed under the Creative Commons Attribution 4.0 License.

drift towards relationships which put female scientists back to their gendered condition, and also to their condition of being a mother in some cases. Some actions related to motherhood only reinforce their outsider position (e.g. "Breastfeeding at conferences" comic strip, Fig. 6). To express breast milk, women often have to make do with rooms that are not designed for it. In the storage room, the lactating mother of the "Breastfeeding at conferences" comic strip is in a position of being somewhere she should not be, like an outsider herself. And even more when someone comes by without respecting her intimacy. The underrepresentation of females creates situations in which such basic needs are not catered for.

\subsection{Objectification of women}

Female researchers are sometimes perceived as objects while their scientific qualification and mental capabilities are com-
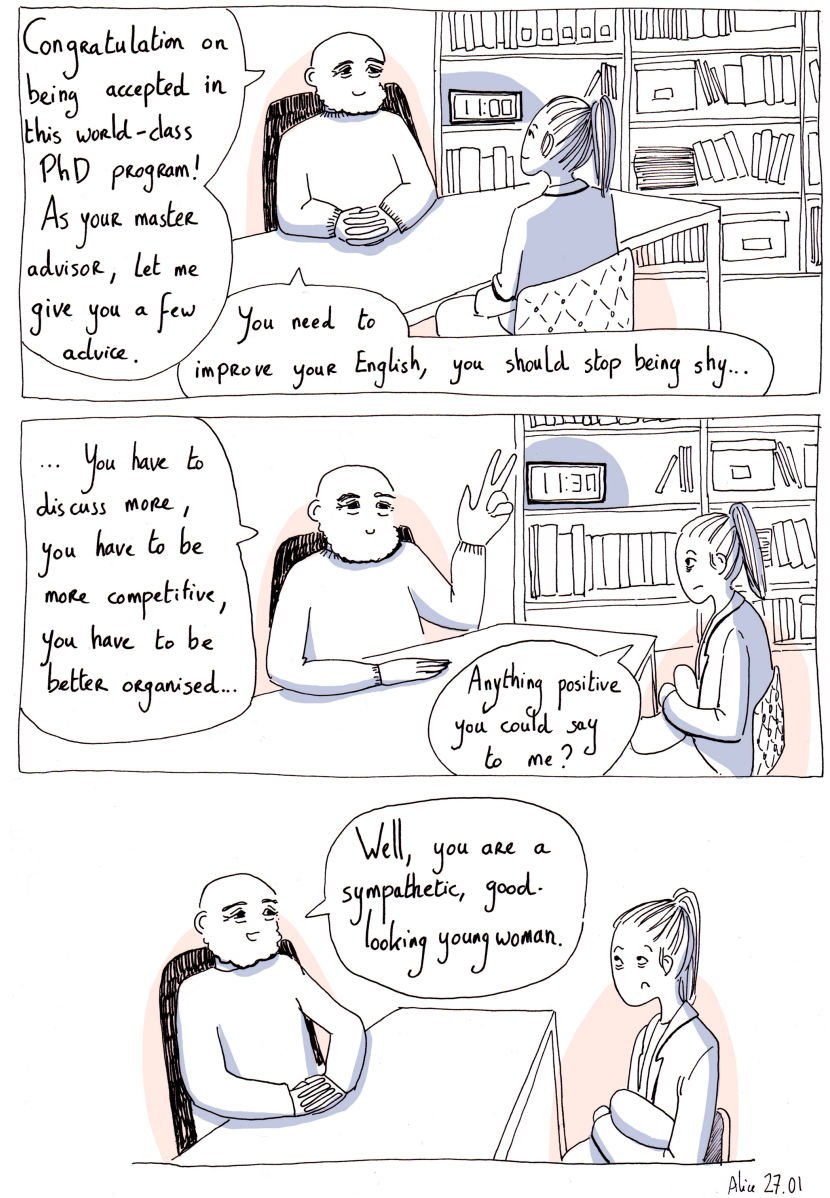

Figure 7. A young female scientist is reduced to her physical appearance. Example of the "Objectification of women" category. Comic strip title: "Good looking young woman" (DTRH team, 2019a; Adenis, 2019). All comics are hand-drawn by Alice Adenis - distributed under the Creative Commons Attribution 4.0 License.

pletely neglected and ignored. In 16 stories (making up $20 \%$ of the accepted stories), women are sexualised and primarily judged based on their appearance. Their personality, expertise, and decision power are put aside while their attractiveness and appearance-based perceptions are highlighted by peers. This is the case for the "Pretty face" comics mentioned earlier. Another example is when a professor tells his student: "You are a sympathetic, good-looking young woman." ("Good looking young woman" comics, Fig. 7) as her only positive attributes.

In addition, we identified misogynous behaviour in a few stories. In one of them, a female body is shamed (unpublished story) and sexual comments are made towards females ("A man's world" comic strip). Beyond any doubt, such behaviour should not be tolerated and accepted neither in the academic environment nor in any societal environment for that matter. 

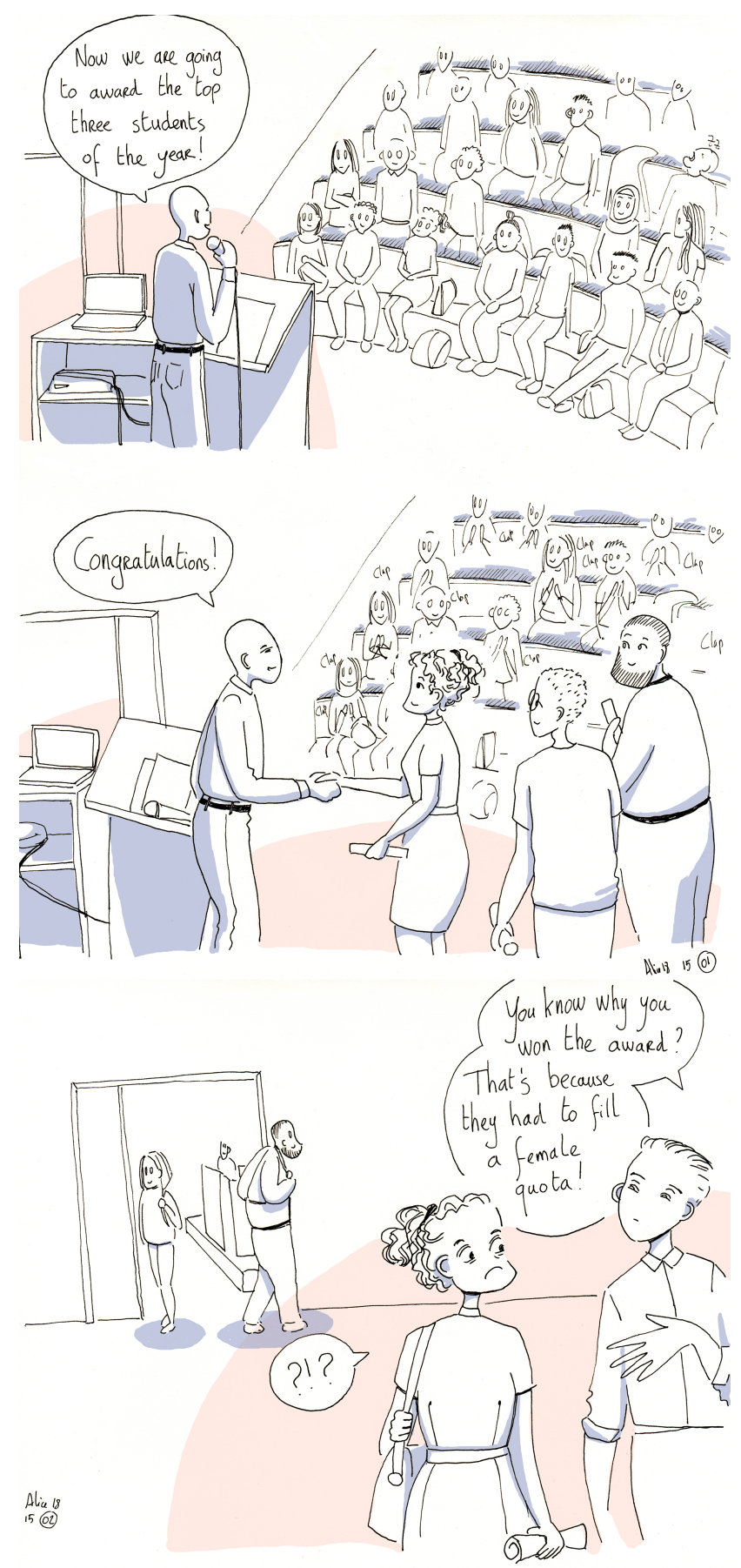

Figure 8. A young female is receiving an award for being among the top three students of her year. Her merit is questioned and attributed to an imaginary female quota. Example of the "Modern sexism and Neosexism" category. Comic strip title: "Female quota" (DTRH team, 2019a; Adenis, 2019). All comics are hand-drawn by Alice Adenis - distributed under the Creative Commons Attribution 4.0 License.

\subsection{Modern sexism and neosexism}

Although awareness of ordinary sexism in science remains to be achieved, scientists are able to recognise the symptoms: an imbalance between women and men for jobs and awards. Therefore, institutions have proposed diverse ways to counter this imbalance. However, such policies have their drawbacks, prescribing females to numbers for quotas or giving an opportunity for scientists to attribute the success of a woman to her gender, even for a selection process that does not perform positive discrimination. $10 \%$ of the testimonies (eight stories) depict situations in which scientists attribute any type of recognition of a woman's work to a result of an antisexist policy. For instance, an award, an invitation to join a project or to give a seminar would have come to fill the female quota ("Being invited" and "Female quota" comics, Fig. 8). In the testimonies, competencies are overlooked and women are considered as a minority that would be so much promoted that men would not be able to get awards, grants or jobs anymore. In a testimony depicting an astronomy class composed of 2 women and 5 men, a classmate says "are they practising some kind of affirmative action this year?" (unpublished testimony). One special situation is proposed in the comic "Nature cover" in which a scientist suggests that the presence of women in the editorial board of Nature would explain why the manuscript of a female scientist gets published. It reverses the traditional sexist situation, claiming women are biased against men.

Again, in a work context, most of these situations put female scientists back to their gendered condition, but this time behind an institutional shield.

\section{Our engagement and communication activities}

Our communication activities essentially consist of an online presence directed to everyone (via our website and through social media) and more specific actions geared towards the scientific community (such as participating in conferences or laboratory seminars) as well as a large non-scientific public (participation in radio programs or round table discussions). These activities are an integral part of the project since our comic strips are based on true stories reported by members of the STEM community.

\subsection{Nature of our engagement and communication actions}

Although the project started in Lyon, France, all members of Did this really happen?! have moved away since then, bringing the project into new institutions, where we propose local presentations and discussions at various occasions. Each member of the group takes any opportunity to talk about the project during a large variety of actions, which has resulted in spreading the project and its main message to a broad audience. 
Since the beginning of the project Did this really happen?! in 2016, we participated in 8 major Earth and Planetary science conferences (hosted by the AGU, the EGU, the Australian Geoscience Council Convention and the European Planetary Science Congress), by presenting either a poster or an oral contribution in the equality and diversity sessions (Coltice and Bocher, 2016; Arnould et al., 2017; Adenis et al., 2018; Gérault et al., 2018; Ulvrova et al., 2019a, b). We also co-organised a short course on gender unconscious biases in Geosciences, using the comics as illustrations of unconscious bias behaviour (Alves de Jesus Rydin et al., 2018, 2019). Taking part in these international conferences is highly valuable since it allows us to have a diverse and broad audience as well as meeting and exchanging with other international scientific and institutional actors of diversity and equality. The development of our project has highly benefited from shared experience with other local, international or institutional members of the scientific community (like the Égalité group at IPGP, France, Égalité group, 2019, and WOMEESA, Australasia, WOMEESA, 2019, 500 Women Scientists, 2019, pod in Zurich and EqualiTea at ETH Zurich, EqualiTea, 2019c). We also published a blog post on unconscious biases in Geosciences (Bocher and Adenis, 2018), and were interviewed for an article about the birth of our project (Bedford, 2018).

All the fore-mentioned actions have mainly been directed to the Earth and Planetary science community to which we all belong. We also made efforts to reach other scientific and non-scientific audiences. First within our university of origin, in Lyon, with the organisation of a day of discussion and conferences around gender equality in science in January 2018 (Sexes égaux, sciences égales?, 2018), and intervention on Radio Brume, a Lyon-based university radio (Sciences pour tous, 2019). We also participated in the Swiss radio show CQFD (Pourquoi il faut plus de filles en sciences, 2019b). We connected with other activists in academia through the participation to an evening on equality in Science (Bocher et al., 2019a), by co-organising Breaking Gender Barriers discussion series (500 Women Scientists, 2019), through the I, scientist conference (Bocher et al., 2019b) and the opportunity to present our initiative to the employees of the the $R e$ searchGate company in Berlin. We were also solicited for an interview by the radio of the Hungarian University of Pest (Ulvrova et al., 2019a).

\subsection{Statistics on our online presence}

Since the launch of our website in January 2018, which marks the start of our internet presence, we have compiled some statistics about the growth of our project (Table 1). We use these to measure and analyse the impact and evolution of our project.

Our website has a central role in our initiative since we use it to publish our comics and news about our actions and to collect testimonies on gender bias in academia from the
STEM community. Since the launch of the website, the annual number of visits has remained stable. In 2018 it reached 19643 views (6377 unique visitors) and we gathered 18625 views (5965 unique visitors) in 2019 (as of 15 November 2019). The website has 39 subscribers. While most of our visitors are from Europe (more than 21800 views, of which 6355 from France, 3941 from Germany and 3938 from the UK), North America (more than 12000 views, of which 10847 from USA) and Oceania (more than 2300 views, of which 2073 from Australia) where the members of the group are located, we are starting to reach people from Africa, Asia and South America. For example, India is currently the 10th country with the largest number of views of our website (508 views).

We use Facebook and Twitter to advertise our actions and our newly posted comics. Those media evince high potential to reach a large audience including scientific and nonscientific public, making our comics accessible and visible to people from countries that we cannot reach via conferences or institutional seminars.

On Twitter, $77 \%$ of our audience is female, while the proportion of female visitors reaches $70 \%$ on Facebook. Our tweets have been viewed 3170 times on average each month (72932 views in total between January 2018 and November 2019), although there are large monthly variations (Fig. 9). Major accounts re-tweeting our project often belong to scientific institutions, individual scientists active on Twitter but also to independent media, artists, and associations actively promoting more diversity and equality. So far, on both social media, the most represented countries are still from Europe (more than $34 \%$ on Twitter and more than $60 \%$ on Facebook), North America (34\% of our audience on Twitter and $23 \%$ of our audience on Facebook) and Oceania (more than $6 \%$ on Twitter and more than $9 \%$ on Facebook). But our project has also reached other countries. For instance, in November 2019, our account has been cited by an influential female Indian author on Twitter and interest from Indian accounts has increased since then.

On Facebook, over the period from 15 May to 15 November 2019, 12 accounts received content from our page per day on average, with seven accounts receiving content about our website through their social connections. Among them, three accounts engaged with our page per day on average (via clicking or commenting on our project).

\subsection{Impact of our actions}

We first started to present our own insider experience as a feminine research team in Earth sciences, so the Earth science community was at first the main contributor to our project. However, the whole academic community is welcome to collaborate on our project by sending us their stories and the diversity of the contributors has increased as the project gained momentum. This way, scientists from diverse fields are involved in the project that further fuels the inter- 
Table 1. Statistics on our web-based presence.

\begin{tabular}{|c|c|c|c|}
\hline Data collected on 15 Nov 2019 & Website & Facebook & Twitter \\
\hline \multicolumn{4}{|l|}{ Total values } \\
\hline$>$ since creation & 38268 & & 72932 \\
\hline$>$ since (date) & & 4367 (since 19 May 2019) & \\
\hline No. of subscribers and followers & 39 via the website/email & 496 followers/464 likes & 712 followers/84 likes \\
\hline $\begin{array}{l}\text { No. of references to our work } \\
\text { (re-tweets/references etc.) }\end{array}$ & $\begin{array}{l}\text { more than } 20 \text { references to } \\
\text { our website }\end{array}$ & $\begin{array}{l}14 \text { links and } 2001 \\
\text { references to our website }\end{array}$ & $\begin{array}{l}2036 \text { references to our web- } \\
\text { site }\end{array}$ \\
\hline \multicolumn{4}{|l|}{ Characteristics of the visitors/tweeters } \\
\hline$>$ dominant gender of the viewers & Unknown & $70 \%$ female & $77 \%$ female \\
\hline$>$ dominant nationalities & $\begin{array}{l}\text { North America, Europe, } \\
\text { Australia }\end{array}$ & $\begin{array}{l}\text { North America, Europe, } \\
\text { Australia }\end{array}$ & $\begin{array}{l}\text { North America, Europe, } \\
\text { Australia }\end{array}$ \\
\hline
\end{tabular}

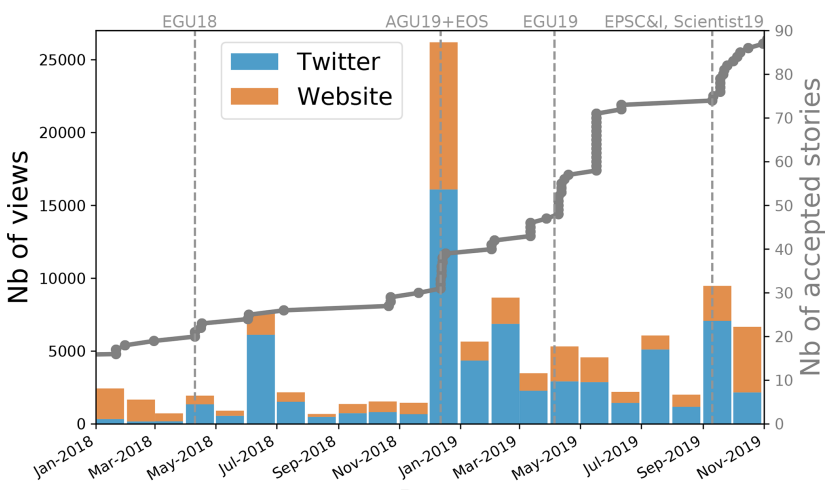

Date

Figure 9. Evolution of the monthly number of views on Twitter and on the website https://didthisreallyhappen.net/ (last access: 9 March 2020, DTRH team, 2019a), and the number of accepted stories (as a function of their date of reception) since the website launch in January 2018. There is a correlation between the high number of views, presentations of the project at international conferences and peaks of reception of testimonies that we accepted. Also, note that the number of views increased significantly after December 2018 as we are getting more attention in the past year. EGU stands for the European Geosciences Union General Assembly in Vienna, AGU for the American Geophysical Union Fall Meeting, and EPSC for the European Planetary Science Congress.

est of the broader academic community in the Did this really happen?! initiative.

Our comic strips describing sexist behaviours are freely available to download (under a Creative Common Attribution-NonCommercial-NoDerivatives 4.0 International License) and print. Their aim is to foster reflections and conversations on gender equality. Recently, we have created a 12-page booklet assembling some of the published comics. We distributed the booklet assembling some of the published comics (available in the Supplement) during conferences (EGU General Assembly 2019, EPSC 2019 and
I, Scientist 2019) to all interested scientists, who brought those printed comics in their laboratories. Moreover, we conduct informal discussions, small presentations, and workshops within our respective institutions and laboratories to raise consciousness about gender inequality in science and promote adequate professional relationships between female and male scientists. From our experience, these discussions have often proved beneficial since the comics trigger reflections on depicted sexist situations and people also start to reflect on their own behaviour. This is a necessary and critical step forward in apprehending sexist biases, aggressions and microaggressions in everyday life. Finally, we also discuss our project while visiting other laboratories. This participates in increasing consciousness about gender inequality in various workplaces.

The number of views on the project's website and our social network accounts varies through time. We observe a significant increase of the number of views and received testimonies after international conferences (Fig. 9). This shows the impact of our interventions, and how the word of mouth propagation participates to the spreading of our project.

The content of our website has been reused or cited more than 30 times on forums (Vis mon job de géologue et chercheure au CNRS, 2019), opinion pieces (Valian, 2019) or institutional websites (Equal Opportunity Committee CRCTR211, 2019). It has also been retweeted or cited more than 2000 times on both Facebook and Twitter. With those social media, it is possible to reach a large audience that is more diverse (in terms of occupation, origin, and ideas) compared to the conferences or local institutions. For example, the largest peaks of views of our project (such as the one in December 2018, Fig. 9) not only coincide with presentations of our project at conferences but also with the advertisement of our website by influential people on social media. 


\subsection{Reactions to our actions}

The majority of the feedback that we have received is very encouraging: "Great initiative. I am a $\mathrm{PhD}$ candidate in geodynamics from India... I recently came across your poster in EGU... Cudos [sic] to the entire team for taking such an innovative initiative in fighting sexism". Many female researchers also identify themselves with situations depicted in our comics. For example, we received: "Dear Colleagues, I just discovered your site via twitter ... looking at your comics [Breastfeeding at a conference] I just can't believe it, it exactly happened to me as well. Thanks for representing it so well." Others acknowledge the fact that our comics made them more mindful of sexist behaviours around them: "You know what? I did not realise until I read your article that I was being discriminated by people from my lab and during congress. I am used to it... So sad..." Such reactions show that our comics can help to bring awareness of unconscious biases simply by showing such situations.

Sometimes people react to our comics by saying that they have never encountered, witnessed or recognised sexist attitudes depicted in the strips. Another type of reaction comprises people that are pessimistic about their own situation and that suffer due to gender stereotypes: "I am a woman and I have 3 children, I [am] completely disappointed, it is toooo much and always what I am doing in the lab is not enough and moreover not appreciated. At home as well whatever I did with my children it is not enough, I need to spend more time with them but I can not. I feel like I am a bad mom and a bad scientist. I need more time to read, to think about what I am doing, to play with my children, to write the thesis, to find a fund after my PhD. I need motivation !!!! I need more $24 \mathrm{~h}$ per day to complete my duties!! In my next life, I will never be a woman". Finally, some of the comments point out that our comics often do not provide any reaction (other than anger, shock and surprise, which almost every time happened to be the real reactions of our contributors) nor provide any solution to the depicted situations: "these cartoons run the risk of portraying women as helpless victims. I think women often do not know how to respond either to doubts cast on their abilities or praise of their abilities. It would be helpful to provide women with possible answers" (Bedford, 2018). We discuss these legitimate concerns in the next section.

\section{Discussion}

We presented the results of two years collecting testimonies on everyday sexism in academia, translating them into comic strips and reporting on our observations (online, during conferences and in research laboratories). The aim of the project is twofold: revealing common patterns of sexism in academia and educating ourselves and others on these instances. Both aspects of the project, the collection of testimonies on one side, and the communication around the project on the other side, are done simultaneously and thus influence each other. Communication on the project is our primary way to gather testimonies, and, in return, new testimonies allow us to reevaluate the different instances of sexism one can encounter in academia. This process makes it possible to gather evidence of everyday sexism within various academic communities while encouraging the members of these communities to actively identify everyday sexism when they experience it.

One limitation of our analysis is the inevitable sources of bias in the testimonies collected: we rely on contributors actively reporting to us. We observe that the participation to the project is biased from (1) the academic discipline of the contributors, (2) their place of work, (3) their gender and (4) the type of sexism reported.

Our contributors tend to come from the Earth science community and mainly work in Europe, USA, and Australia, which are places where members of the project are currently working. Our ongoing efforts to eliminate this bias include participating in conferences that are not specific to the Earth Science community (e.g. the I, Scientist conference), and also growing our influence on social networks.

The third bias observed is the gender bias in both contributors and the public reached through social networks: so far, we have mainly reached women (more than $70 \%$ of the views on our social media accounts, and $97.8 \%$ of accepted testimonies come from women). The very low percentage of male testimonies might mean that men are not noticing everyday sexism, or do not identify it as such. The second hypothesis seems to be supported by the study of Becker and Swim (2011) who found that American male college students encountered the same amount of sexist remarks as their female counterparts, but, on average, considered them less sexist. Drury and Kaiser (2014) provide an extensive review of male detection of sexism and intervention. In particular, they identify two characteristics that tend to play a major role in male observer's detection of sexism and intervention: the rejection of legitimising beliefs (i.e. the belief that one's success is due to internal factors such as talent, hard work, and other intrinsic qualities) and the communal orientation (i.e. the tendency of individuals to focus on the well-being of others without expecting direct benefit from it). We suppose that the same mechanisms should lead men to contribute to our project, and thus plan on modifying the presentation of our project to appeal to both aspects (rejection of legitimising beliefs and communal orientation) by clarifying (1) how sexist bias might affect the career of women, and (2) how our project can contribute to changing behaviours in academia. The results described in Hardacre and Subašić (2018) and Subašić et al. (2018) point towards one potential additional solution. They show that although framing the inequality issue as a common problem for both genders rather than as a women's issue increases the legitimacy of leaders, an important aspect to convince men and women to take action is to 
have the support of male leaders. We plan to integrate these adjustments in future presentations of the project.

The fourth bias concerns the type of sexism that is reported. The study of Williams et al. (2014) provides statistics of recurrent gender bias experienced by women in academia, based on interviews conducted on sixty women in the USA. This study offers a reference to which we can compare the testimonies that we received and allows us to identify potential blind spots. However, we cannot compare directly the proportions given in their studies with our numbers since their classification is different, and the numbers provided refer to the proportion of women that have encountered a given bias, while we report on the proportion of a given bias within the testimonies collected.

In agreement with Williams et al. (2014), we find a prevalence of the "prove it again" bias, which corresponds to the category that we named "Questioning Female competence" ( $66.7 \%$ of interviewees versus $57 \%$ of collected testimonies). Most of the behaviours that we identify as "behaviours that aim at maintaining women in stereotypical feminine roles" $(69 \%)$ belong in their studies to the "Maternal Wall" (64\%) and to the "reported pressure to take on deadend traditionally feminine roles" (34.1\%).

We also identified several types of bias that were not reported as such in Williams et al. (2014). First, we chose to include instances in which the pressure is on men to conform to typically masculine stereotypes. We consider that, in order to move beyond the stereotypical gender role assignments, it is also important to address it and include men in the conversation, as argued earlier in the discussion. Secondly, Williams et al. (2014) report on a sense of isolation among women of colour, but much less among white women. We identified 19 stories that depicted women as outsiders, but we did not collect information on the skin colour of contributors. Finally, $10 \%$ of our stories reported modern sexist or neosexist views, a category which is absent from Williams et al. (2014).

On the contrary, several biases reported by Williams et al. (2014) are underrepresented in our testimonies. For example, they report that $55.3 \%$ of women scientists witnessed "tug-of-war" patterns, which are tensions between female professionals arising from gender bias, such as the "queen bee syndrome" (Staines et al., 1974), when a senior female professional is tougher towards female subordinates. We have not received any testimony describing this pattern. Overall we received very few testimonies in which women behave in a sexist manner, while sexist bias in women exists and can be higher than men's in some instances (Ellemers et al., 2004). Several studies have shown that ambiguous sexist behaviour was harder to detect when the perpetrator was a woman (Baron et al., 1991; Sterk et al., 2018), which could explain the absence of such testimonies. Williams et al. (2014) also report the prevalence of sexual harassment encountered (34.5\% of interviewees) while only 2 received testimonies qualify as sexual harassment (although $20 \%$ of our testimonies contained behaviours related to the objectification of women). One plausible explanation is self-censorship, according to the personal discussions we had with potential contributors who had endured or witnessed sexual harassment in the workplace. They often feared to be recognised and also considered that comics are not the adequate support for these terrible stories.

Considering these aspects, our project should be seen as an incomplete picture of what everyday sexism can look like in academia, the statistics reported in Sect. 2 do not necessarily reflect the proportions of different types of sexism experienced by women in academia. For our future interventions, we plan to draw examples from the aforementioned literature to fill the gaps in stereotypes representation and encourage our audience to consider all types of sexism.

Comic strips are a good way to give visibility to issues that are usually overlooked. Our project is centred on sexism in academia but could be extended to consider other types of prejudices, both independently from sexism, but also from an intersectional point of view (Crenshaw, 1989). Bernard and Cooperdock (2018) provide an alarming synthesis on the state of ethnic diversity in Earth Sciences in the US, with no apparent improvement for the past 40 years. It is difficult to estimate the situation in Europe given the absence of unified ethnic statistics for historical and data protection reasons (Simon, 2012), but there is no reason to expect a better representation of people of colour. Concerning the situation of LGBTQ in science, although the general society's opinion has made progress in some countries, a survey of UK physical scientists reported that $28 \%$ of LGBT+ respondents "considered leaving their workplace because of the climate or discrimination towards LGBT+ people" (Dyer et al., 2019). This proportion rose to almost $50 \%$ for trans scientists. Representing in a graphic form the struggles that the LGBTQ community faces could help the rest of academia connect, empathise and become more inclusive. Likewise, comics could be an efficient way to convey the experience of disabled scientists and bring cognizance on intentional and unintentional ableism, for example during conferences (Fleming, 2019). Beyond the specific discriminatory behaviours that are based on stereotypes against these different categories, we expect to find common ground in the situation of feeling like an outsider and being asked to prove again and again competence in science. For people to contribute to our project in these directions, we need to rethink our communication strategies, but also put more resources and energy into this project, which is challenging since we all act on a voluntary basis and have no dedicated time or funding for it.

The primary goal of our comics is to depict the situation to our readers. Oftentimes, the contributors are left surprised and shocked by the sexist comments or attitude, and there is a risk of consistently representing women as helpless victims. The bystander intervention approach shows great results in empowering women and men to fight against un- 
conscious biases (Powel, 2011). Initiatives like ADVANCEGeo bring these much needed strategies to our community (ADVANCEGeo, 2020). We also participate in this effort through complementary activities and discussions within our laboratories and at conferences. The communication on our project uses three main modalities: (1) advertisement through social media, (2) traditional communication practices of academia (mobility of researchers, visit of collaborators, international conferences) and (3) institutional EqualityDiversity-Inclusion (EDI) initiatives. We reflect hereafter on the importance of each of these modalities to spread our message and develop common strategies of change with other activists.

Over the last two decades, the ease of sharing information to a wide audience online, especially using social media, has allowed the rise of powerful feminist movements, aiming at talking about sexual harassment and aggressions, rape culture and everyday sexism, the most well known and groundbreaking being the \#Metoo movement. Within academia, courageous researchers raised their voices to speak out about their harassment experiences and push institutions to act (see for example Jahren, 2016, Wadman, 2017, and Wadman, 2018). Alongside exposing these dreadful stories, we believe it is also important to put a focus on more mundane instances of everyday sexism and microaggressions, in the spirit of the international everyday sexism project, for example (Everyday Sexism Project, 2019b). The dynamics of the online community and solidarity of different initiatives and activists helped us tremendously to amplify our message, as reported in Sect. 3.

Additionally, this project has developed in its current form because the necessary spaces existed within the academic world for it to emerge and grow. Two factors played a major role in the inception of this project. First, the presence of the equality-diversity and communication services at the University Claude Bernard of Lyon (Mission égalité - diversité, 2019a) and the availability of two of their members, Philippe Liotard and Chloe Schweyer, were crucial to our evolution from a group of scientists experiencing gender bias to activists for gender equality and diversity and inclusion in academia. With their help, our informal exchanges on the everyday sexism that we experienced played the role of a consciousness-raising group, as they were used by secondwave feminism to identify a common pattern of oppression in the society (Sarachild, 1968). The second element was the solicitation from ERC program officer Claudia Alves de Jesus-Rydin to present our experience as an ERC-funded team at the EGU General Assembly, in a session entitled "Promoting and supporting equality of opportunities in geosciences" (Coltice and Bocher, 2016). Both of these factors led us to release the first set of comics, one year later, at the same EGU session (Arnould et al., 2017).

Likewise, other spaces and periods created within the academic life allowed us to develop our project and raise our ambitions. Most of us are currently working as researchers. We leverage our collaboration relationships, and take advantage of visits of and to other researchers to communicate on the project, informally, but also during scientific presentations. More importantly, the relative increase of the diversity of backgrounds of academic employees and the change in mentalities makes it more common to have dedicated EqualityDiversity-Inclusion groups within laboratories and institutions. These groups play a crucial role in spreading information and creating initiatives from the local scale to the international scale.

Holmes (2015) uses the framework of Risman (2004) to understand the barriers that women face in academia, with three levels at which women can find barriers to their professional development: the institutional, the interactional and the individual levels. Generally, institutions develop solutions to these different types of barriers with a mainly topdown approach (Buitendijk et al., 2019). However, the development of our project shows how institutional structures can create opportunities for individual or grass-root actions to emerge and grow. Research has shown that diversity, equality and inclusion improve when all the members of an institution feel they are actors of change (Dobbin and Kalev, 2016). For it to be possible, it is important that institutions support and encourage grass-root initiatives that promote EDI.

\section{Conclusions}

The project Did this really happen?! was created in 2016 by a team of seven scientists working on the geodynamics of Earth's mantle and lithosphere. After having faced sexists microaggressions, discussions arose internally to address these everyday issues. We chose to report on these sexist situations through comic strips. This communication tool has the benefit of being approachable and engaging while showing the situations without the need for explanations or interpretations. Between 2016 and 2019, we have received 103 testimonies, from which 89 have been accepted, and 23 published. From this sample of sexist biases collected from the scientific community, we are now able to analyse with more details the types of stereotypes that are still common in our research environments. We have classified the stories into six non-exclusive categories of sexist biases: (1) those which maintain females to stereotypical roles, (2) those which confine males to stereotypical roles, (3) those which question female competencies, (4) those which keep women as outsiders in networking contexts, (5) those which objectify women and (6) those which show the backlash of antisexist policies. We found that although all these sexist biases are well represented, whatever the age of the contributor, the country, and the context in which these situations took place, the majority of the comics $(70 \%)$ follows a situation in which women scientists are defined upon physical stereotypes. The second most common feature is the questioning of female abilities $(61 \%)$. Male stereotypes are present in almost half of the 
comics $(41 \%)$ while the other categories are less represented. Although modern sexism is not represented abundantly in the comics, it provoked the most controversial feedback that we have received on this project.

The large number of testimonies depicting recurring sexist situations suggests that such behaviours are still widespread, and we advocate for more vigilance and actions to fight against sexism in the workplace. These comics can help to point out (un)conscious biases at work. While women are currently more sensitive to these questions (based on the online presence, they represent more than $70 \%$ of our audience on social media and more than $95 \%$ of our contributors), one of our objectives is to encourage men to take an active role in addressing sexism by testifying.

The short term goal of the team is to produce a more complete picture of everyday sexism in academia by producing new comics from the received testimonies. We will also improve our diffusion and communication materials so as to increase the accessibility of the project and to promote their use by research institutions. To do that, we will provide opensource presentations and workshops, including comics and bibliography on gender equality. We also plan to design a short movie on "unconscious bias in academia" to improve the visibility of our cause. Another main objective is to leverage the increasing number of followers to extend the scope of the project to other discriminations. We intend to encourage discussions with other minorities but are also using our everyday proximity with the students to increase their sensitivity on sexists bias and inappropriate behaviours in the academic world. We encourage them to be proactive and are confident as this generation already stands up for what they believe in and embraces equality and inclusion values.

Data availability. In order to preserve the anonymity of contributors, the data used for this article cannot be shared.

Supplement. The supplement related to this article is available online at: https://doi.org/10.5194/adgeo-53-15-2020-supplement.

Author contributions. AA drew all the comics. All authors participated in the collection of testimonies and communication activities. MU, MA, MG, NC and MB participated in data collection and the statistical analysis of the project. MB, MU, MA, NC, and CM contributed to the redaction of the article.

Competing interests. The authors declare that they have no conflict of interest.

Special issue statement. This article is part of the special issue "Diversity and equality in the geosciences (EGU2019 EOS6.1 \& US4,
AGU2018 ED41B, JpGU2019 U-02)". It is a result of the EGU General Assembly 2019, Vienna, Austria, 7-12 April 2019.

Acknowledgements. All comics are hand-drawn by Alice Adenis distributed under the Creative Commons Attribution 4.0 License. This work is volunteer-based. We are thankful to Claudia Alves de Jesus-Rydin who gave us the spark to start our adventure and support to continue, Philippe Liotard and Cléo Schweyer who guided us in the very beginning of the project, and to Mary Anne Holmes and Johanna Stadmark who improved this manuscript through careful review. Last but not least, we would like to thank all the anonymous contributors without whom the project would not exist.

Review statement. This paper was edited by Claudia Jesus-Rydin and reviewed by Mary Anne Holmes and Johanna Stadmark.

\section{References}

500 Women Scientists Zurich pod: 500 Women Scientists Zurich pod, available at: https://baug.ethz.ch/en/department/ governance/gender-and-diversity/500-women-scientists.html, last access: 9 March 2020.

500 Women Scientists: 500WS "Breaking the Gender Barriers,", available at: https://video.ethz.ch/events/2019/ws500.html, last access: 30 November 2019a.

Adenis, A.: Entrelacs, available at: https://entrelacsbd.wordpress. com/, last access: 20 November, 2019.

Adenis, A., Arnould, M., Bocher, M., Coltice, N., Gérault, M., Mallard, C., and Ulvrova, M.: didthisreallyhappen.net: Fighting everyday sexism in academia, one comic strip at a time,Geophysical Research Abstracts Vol. 20, EGU2018-18456, EGU General Assembly, available at: https://meetingorganizer. copernicus.org/EGU2018/EGU2018-18456.pdf (last access: 9 March 2020), 2018.

ADVANCEGeo Partnership, available at: https://serc.carleton.edu/ advancegeo/about.html, last access: 9 February, 2020.

Alves de Jesus Rydin, C., Montanari, A., Bocher, M., and Gallego Torres, D.: Unconscious bias, available at: https:// meetingorganizer.copernicus.org/EGU2018/session/28942 (last access: 9 March 2020), 2018.

Alves de Jesus Rydin, C., Conley, D., and Bocher, M.: Unconscious bias, available at: https://meetingorganizer.copernicus. org/EGU2019/session/30877, last access: 20 November, 2019.

Arnould, M., Bocher, M., Coltice, N., Gérault, M., Mallard, C. and Ulvrova, M.: Beyond statistics: local solutions to the underrepresentation of women in Geophysics, Geophysical Research Abstracts, Vol. 19, EGU2017-17770, 2017.

Ashburn-Nardo, L. and Abdul Karim, M. F.: 2 - The CPR model: Decisions involved in confronting prejudiced responses, in Confronting Prejudice and Discrimination, edited by: Mallett, R. K. and Monteith, M. J., Academic Press, 29-47, 2019.

Asplund, M. and Welle, C. G.: Advancing Science: How Bias Holds Us Back, Neuron, 99, 635-639, https://doi.org/10.1016/j.neuron.2018.07.045, 2018. 
Baron, R. S., Burgess, M. L., and Kao, C. F.: Detecting and labeling prejudice: Do female perpetrators go undetected?, Pers. Soc. Psychol. Bull., 17, 115-123, 1991.

Becker, J. C. and Swim, J. K.: Seeing the unseen: Attention to daily encounters with sexism as a way to reduce sexist beliefs, Psychol. Women Q., 35, 227-242, https://doi.org/10.1177/0361684310397509, 2011.

Bedford, B.: Illustrating Casual Sexism in Science, EOS, 99, https://doi.org/10.1029/2018EO111589, 2018.

Bernard, R. E. and Cooperdock, E. H. G.: No progress on diversity in 40 years, Nat. Geosci., 11, 292-295, https://doi.org/10.1038/s41561-018-0116-6, 2018.

Biggs, J., Hawley, P. H. and Biernat, M.: The Academic Conference as a Chilly Climate for Women: Effects of Gender Representation on Experiences of Sexism, Coping Responses, and Career Intentions, Sex Roles, 78, 394-408, https://doi.org/10.1007/s11199-017-0800-9, 2018.

Bocher, M. and Adenis, A.: Help us fight patriarchy, one comic strip at a time!, EGU Geodyn. Blog, available at: https://blogs.egu.eu/divisions/gd/2018/03/21/ help-us-fight-patriarchy-one-comic-strip-at-a-time/ (last access: 20 November 2019), 2018.

Bocher, M., Adenis, A., Arnould, M., Coltice, N., Gérault, M., Mallard, C., and Ulvrova, M.: Did this really happen?!, available at: https://m.facebook.com/events/2402908089942941/ (last access: 9 March 2020), 2019a.

Bocher, M., Adenis, A., Arnould, M., Coltice, N., Gérault, M., Mallard, C., and Ulvrova, M.: Feminist activism in academia: A grassroot initiative perspective, available at: https://www. iscientist.berlin/ (last access: 9 March 2020), 2019b.

Buitendijk, S., Curry, S., and Maes, K.: Equality, diversity and inclusion at universities: the power of a systemic approach, available at: https://www.leru.org/publications/ equality-diversity-and-inclusion-at-universities, last access: 22 November, 2019.

Burgess, D. and Borgida, E.: Who women are, who women should be: Descriptive and prescriptive gender stereotyping in sex discrimination, Psychol. Public Policy Law, 5, 665-692, https://doi.org/10.1037/1076-8971.5.3.665, 2000.

Castilla, E. J. and Benard, S.: The Paradox of Meritocracy in Organizations, Adm. Sci. Q., 55, 543-676, https://doi.org/10.2189/asqu.2010.55.4.543, 2010.

Ceci, S. J., Ginther, D. K., Kahn, S., and Williams, W. M.: Women in Academic Science: A Changing Landscape, Psychol. Sci. Public Interest J. Am. Psychol. Soc., 15, 75-141, https://doi.org/10.1177/1529100614541236, 2014.

Chávez, K. and Mitchell, K. M. W.: Exploring Bias in Student Evaluations: Gender, Race, and Ethnicity, PS Polit. Sci. Polit., 1-5, https://doi.org/10.1017/S1049096519001744, 2019.

Clancy, K. B. H., Lee, K. M. N., Rodgers, E. M., and Richey, C.: Double jeopardy in astronomy and planetary science: Women of color face greater risks of gendered and racial harassment, J. Geophys. Res.-Planet., 122, 1610-1623, https://doi.org/10.1002/2017JE005256, 2017.

Coltice, N. and Bocher, M.: Growing up as a feminine team through a European project, EGU General Assembly 2016, Vienna Austria, 17-22 April, 2016, EPSC2016-14722, 2016.

Crenshaw, K.: Demarginalizing the intersection of race and sex: A black feminist critique of antidiscrimination doctrine, feminist theory and antiracist politics, Univ. Chic. Leg. Forum, 1989, 131, 1989.

Dobbin, F. and Kalev, A.: Why diversity programs fail and what works better, Harvard Business Review, 94, 52-60, 2016.

Drury, B. J. and Kaiser, C. R.: Allies against sexism: The role of men in confronting sexism, J. Soc. Issues, 70, 637-652, https://doi.org/10.1111/josi.12083, 2014.

DTRH team: Did this really happen?!, available at: https:// didthisreallyhappen.net/, last access: 20 November, 2019a).

Dutt, K., Pfaff, D. L., Bernstein, A. F., Dillard, J. S., and Block, C. J.: Gender differences in recommendation letters for postdoctoral fellowships in geoscience, Nat. Geosci., 9, 805-808, https://doi.org/10.1038/ngeo2819, 2016.

Dyer, J., Townsend, A., Kanani, S., Matthews, P., Palermo, A., Farley, S. and Thorley, C.: Exploring the workplace for LGBT+ Physical Scientists, Institute of Physics, Royal Astronomical Society and Royal Society of Chemistry, 52 pp., 2019.

Eagly, A. H. and Mladinic, A. : Are people prejudiced against women? Some answers from research on attitudes, gender stereotypes, and judgments of competence, Eur. Rev. soc. Psychol., 5, 1-35, https://doi.org/10.1080/14792779543000002, 1994.

Eagly, A. H. and Wood, W.: Social Role Theory, in Handbook of Theories of Social Psychology,SAGE Publications Ltd, London, UK, 458-476, 2012.

Égalité group: Égalité group website, available at: https://www. facebook.com/EgaliteIPGP/, last access: 20 November, 2019.

Ellemers, N., den Heuvel, H. V., de Gilder, D., Maass, A., and Bonvini, A.: The underrepresentation of women in science: Differential commitment or the queen bee syndrome?, Br. J. Soc. Psychol., 43, 315-338, https://doi.org/10.1348/0144666042037999, 2004.

Equal Opportunity Committee CRC-TR211: Equal Opportunity Committee CRC-TR211, available at: https://itp.uni-frankfurt. de/ strongmatter/\#Equality, last access: 20 November, 2019.

EqualiTea: EqualiTea, available at: https://www.vame-erdw.ethz. ch/initiatives-and-working-groups/equalitea/, last access: 24 November, 2019.

Everyday Sexism Project: Everyday Sexism Project, available at: https://everydaysexism.com/, last access: 29 November, 2019.

Fleming, N.: How to organize a conference that's open to everyone, Nature, 571, S46-S47, https://doi.org/10.1038/d41586-01902253-9, 2019.

Ford, H. L., Brick, C., Blaufuss, K., and Dekens, P. S.: Gender inequity in speaking opportunities at the American Geophysical Union Fall Meeting, Nat. Commun., 9, 1-6, https://doi.org/10.1038/s41467-018-03809-5, 2018.

Gérault, M., Adenis, A., Arnould, M., Bocher, M., Coltice, N., Mallard, C., and Ulvrova, M.: didthisreallyhappen.net: Fighting everyday sexism in academia, one comic strip at a time, AGU Fall Meeting Abstracts 2018, ED21A-09, https://ui. adsabs.harvard.edu/abs/2018AGUFMED21A..09G/abstract (last access: 9 March 2020), 2018.

Glick, P., Fiske, S. T., Mladinic, A., Saiz, J. L., Abrams, D., Masser, B., Adetoun, B., Osagie, J. E., Akande, A., Alao, A., Annetje, B., Willemsen, T. M., Chipeta, K., Dardenne, B., Dijksterhuis, A., Wigboldus, D., Eckes, T., Six-Materna, I., Expósito, F., Moya, M., Foddy, M., Kim, H.-J., Lameiras, M., Sotelo, M. J., Mucchi-Faina, A., Romani, M., Sakalli, N., Udegbe, B., Yamamoto, M., Ui, M., Ferreira, M. C., and López, W. L.: 
Beyond prejudice as simple antipathy: Hostile and benevolent sexism across cultures, J. Pers. Soc. Psychol., 79, 763-775, https://doi.org/10.1037/0022-3514.79.5.763, 2000.

Greider, C. W., Sheltzer, J. M., Cantalupo, N. C., Copeland, W. B., Dasgupta, N., Hopkins, N., Jansen, J. M., JoshuaTor, L., McDowell, G. S., Metcalf, J. L., McLaughlin, B., Olivarius, A., O'Shea, E. K., Raymond, J. L., Ruebain, D., Steitz, J. A., Stillman, B., Tilghman, S. M., Valian, V., VillaKomaroff, L., and Wong, J. Y.: Increasing gender diversity in the STEM research workforce, Science, 366, 692-695, https://doi.org/10.1126/science.aaz0649, 2019.

Haines, E. L., Deaux, K., and Lofaro, N.: The Times They Are Changing ... or Are They Not? A Comparison of Gender Stereotypes, 1983-2014, Psychol. Women Q., 40, 353-363, https://doi.org/10.1177/0361684316634081, 2016.

Handley, I. M., Brown, E. R., Moss-Racusin, C. A., and Smith, J. L.: Quality of evidence revealing subtle gender biases in science is in the eye of the beholder, P. Natl. Acad. Sci. USA, 112, 1320113206, https://doi.org/10.1073/pnas.1510649112, 2015.

Hardacre, S. L. and Subašić, E.: Whose Issue Is It Anyway? The Effects of Leader Gender and Equality Message Framing on Men's and Women's Mobilization Toward Workplace Gender Equality, Front. Psychol., 9, 2497, https://doi.org/10.3389/fpsyg.2018.02497, 2018.

Hentschel, T., Heilman, M. E., and Peus, C. V.: The Multiple Dimensions of Gender Stereotypes: A Current Look at Men's and Women's Characterizations of Others and Themselves, Front. Psychol., 10, 11, https://doi.org/10.3389/fpsyg.2019.00011, 2019.

Holmes, M. A.: A Sociological Framework to Address Gender Parity, in: Women in the geosciences: practical, positive practices toward parity, edited by: Holmes, M. A., Oconnel, S., and Kuheli, D., AGU, Wiley, https://doi.org/10.1002/9781119067573.ch3, 2015.

Jahren, A. H.: She Wanted to Do Her Research. He Wanted to Talk "Feelings", New York Times, available at: https://www.nytimes.com/2016/03/06/opinion/sunday/ she-wanted-to-do-her-research-he-wanted-to-talk-feelings. html?auth=login-google \& smid=tw-nytopinion\&smtyp=cur (last access: 3 February 2020), 2016.

John, K. S., Riggs, E., and Mogk, D.: Sexual Harassment in the Sciences: A Call to Geoscience Faculty and Researchers to Respond, J. Geosci. Educ., 64, 255-257, https://doi.org/10.5408/1089-9995-64.4.255, 2016.

Kaatz, A., Lee, Y. G., Potvien, A., Magua, W., Filut, A., Bhattacharya, A., Leatherberry, R., Zhu, X., and Carnes, M.: Analysis of National Institutes of Health R01 Application Critiques, Impact, and Criteria Scores: Does the Sex of the Principal Investigator Make a Difference?, Acad. Med. J. Assoc. Am. Med. Coll., 91, 1080-1088, https://doi.org/10.1097/ACM.0000000000001272, 2016.

Lerback, J. and Hanson, B.: Journals invite too few women to referee, Nature, 541, 455-457, https://doi.org/10.1038/541455a, 2017.

Miller, D. I., Eagly, A. H., and Linn, M. C.: Women's representation in science predicts national gender-science stereotypes: Evidence from 66 nations, J. Educ. Psychol., 107, 631-644, https://doi.org/10.1037/edu0000005, 2014.
Mission égalité - diversité: Mission égalité - diversité, Mission Égal. - Divers. - Univ. Claude Bernard Lyon 1, available at: https://egalite-diversite.univ-lyon1.fr/, last access: 24 November, 2019a.

Monroe, K. R., Choi, J., Howell, E., Lampros-Monroe, C., Trejo, C., and Perez, V.: Gender Equality in the Ivory Tower, and How Best to Achieve It, PS Polit. Sci. Polit., 47, 418-426, https://doi.org/10.1017/S104909651400033X, 2014.

Moss-Racusin, C. A., Dovidio, J. F., Brescoll, V. L., Graham, M. J., and Handelsman, J.: Science faculty's subtle gender biases favor male students, Proc. Natl. Acad. Sci. USA, 109, 16474-16479, 2012.

Moss-Racusin, C. A., Toorn, J. van der, Dovidio, J. F., Brescoll, V. L., Graham, M. J., and Handelsman, J.: Scientific Diversity Interventions, Science, 343, 615-616, https://doi.org/10.1126/science.1245936, 2014.

Moss-Racusin, C. A., Sanzari, C., Caluori, N., and Rabasco, H.: Gender Bias Produces Gender Gaps in STEM Engagement, Sex Roles, 79, 651-670, https://doi.org/10.1007/s11199-018-0902-z, 2018.

Popp, A. L., Lutz, S. R., Khatami, S., van Emmerik, T. H. M., and Knoben, W. J. M.: A Global Survey on the Perceptions and Impacts of Gender Inequality in the Earth and Space Sciences, Earth Space Sci., 6, 1460-1468, https://doi.org/10.1029/2019EA000706, 2019.

Pourquoi il faut plus de filles en sciences: Pourquoi il faut plus de filles en sciences, CQFD, available at: https://pages.rts.ch/la-1ere/programmes/cqfd/ 10098548-pourquoi-il-faut-plus-de-filles-en-sciences-10-01-2019. html?mediaShare=1, last access: 20 November, 2019.

Powell, A.: Review of Bystander Approaches in Support of Preventing Violence Against Women, Victoria Health Promotion Foundation, Victoria, New South Wales, Publication P-052V B, available at: http://www.ncdsv.org/images/VicHealth_ ReviewBystanderApproachesSupportPreventingVAW_5-2011. pdf (last access: 9 February 2020), 2011.

Régner, I., Thinus-Blanc, C., Netter, A., Schmader, T., and Huguet, P.: Committees with implicit biases promote fewer women when they do not believe gender bias exists, Nat. Hum. Behav., 3, 1171-1179, https://doi.org/10.1038/s41562-019-0686-3, 2019.

Risman, B. J.: Gender as a social structure: Theory wrestling with activism, Gender Soc., 18, 429-450, https://doi.org/10.1177/0891243204265349, 2004.

Sarachild, K.: A Program For Feminist "Consciousness Raising", 1968.

Sciences pour tous: Où sont les femmes? Quelle place pour les femmes dans la recherche?, available at: https://sciencespourtous.univ-lyon1.fr/ sciences-lemission-place-femmes-sciences/?doing_wp_cron= 1574028322.0250759124755859375000 (last access: 20 November, 2019.

Sexes égaux, sciences égales?? Sexes égaux, sciences égales??, Popsciencesuniversite-Lyon, available at: https://popsciences. universite-lyon.fr/agenda/sexes-egaux-sciences-egales/ (last access: 24 November 2019), 2018.

Sheltzer, J. M. and Smith, J. C.: Elite male faculty in the life sciences employ fewer women, P. Natl. Acad. Sci. USA, 111, 10107-10112, https://doi.org/10.1073/pnas.1403334111, 2014. 
Simon, P.: Collecting ethnic statistics in Europe: a review, Ethn. Racial Stud., 35, 1366-1391, https://doi.org/10.1080/01419870.2011.607507, 2012.

Staines, G., Tavris, C. and Jayaratne, T. E.: The queen bee syndrome, Psychology Today, 7, 55-60, 1974.

Sterk, N., Meeussen, L., and Van Laar, C.: Perpetuating Inequality: Junior Women Do Not See Queen Bee Behavior as Negative but Are Nonetheless Negatively Affected by It, Front. Psychol., 9, 1690, https://doi.org/10.3389/fpsyg.2018.01690, 2018.

Subašić, E., Hardacre, S., Elton, B., Branscombe, N. R., Ryan, M. K., and Reynolds, K. J.: "We for She": Mobilising men and women to act in solidarity for gender equality, Group Process. Intergroup Relat., 21, 707-724, https://doi.org/10.1177/1368430218763272, 2018.

Swim, J. K., Aikin, K. J., Hall, W. S., and Hunter, B. A.: Sexism and Racism: Old-Fashioned and Modern Prejudices, J. Pers. Soc. Psychol., 68, 199-214, https://doi.org/10.1037/00223514.68.2.199, 1995.

Tougas, F., Brown, R., Beaton, A. M., and Joly, S.: Neosexism: Plus Ça Change, Plus C'est Pareil, Pers. Soc. Psychol. Bull., 21, 842849, https://doi.org/10.1177/0146167295218007, 1995.

Troy, V.: Sexism in the Academy, $n+1$, (34), available at: https:// nplusonemag.com/issue-34/essays/sexism-in-the-academy/ (last access: 20 November, 2019.

Uhlmann, E. L. and Cohen, G. L.: "I think it, therefore it's true": Effects of self-perceived objectivity on hiring discrimination, Organ. Behav. Hum. Decis. Process., 104, 207-223, https://doi.org/10.1016/j.obhdp.2007.07.001, 2007.

Ulvrova, M., Gérault, M., and Bocher, M.: Did this really happen? Female researchers share their discrimination stories in comic strips, available at: http://eper.elte.hu/index.php/2019/09/23/didthis-really-happen-woman-scientists-share-their-discriminationstories-in-a-series-of-comic-strips/, last access: 20 November, 2019a.
Ulvrova, M., Adenis, A., Arnould, M., Bocher, M., Coltice, N., Gérault, M., and Mallard, C.: Promoting gender equality in academia through comic strips, Geophysical Research Abstracts Vol. 21, EGU2019-14644-2, 2019 EGU General Assembly 2019, available at: https://meetingorganizer.copernicus.org/EGU2019/ EGU2019-14644-2.pdf (last access: 9 March 2020), 2019b.

Valian, V.: We are all complicit in harassment and abuse, Nature, 574, 7-7, https://doi.org/10.1038/d41586-019-02944-3, 2019.

Vis mon job de géologue et chercheure au CNRS: Vis mon job de géologue et chercheure au CNRS, available at: https://forums.rockiemag.com/threads/ vis-mon-job-de-geologue-et-chercheure-au-cnrs.821/, last access: 20 November, 2019.

Wadman, M.: A cold case, Science, 358, 162-165, https://doi.org/10.1126/science.358.6360.162, 2017.

Wadman, M.: Report details harassment by famed biologist, Science, 361, 316-317, https://doi.org/10.1126/science.361.6400.316, 2018.

Williams, J. C.: Bias Interrupters - Small Steps, Big Change, available at: https://biasinterrupters.org/, last access: 23 November, 2019.

Williams, J. C., Phillips, K. W., and Hall, E. V.: Double Jeopardy? Gender Bias Against Women in Science, Worklife Law, available at: https://worklifelaw.org/publication/ double-jeopardy-gender-bias-against-women-of-color-in-science/ (last access: 19 November 2019), 2014.

WOMEESA: WOMEESA, available at: https://www.womeesa.net/, last access: 20 November, 2019. 